Article

\title{
Analysis of the Environmental Efficiency of the Chinese Transportation Sector Using an Undesirable Output Slacks-Based Measure Data Envelopment Analysis Model
}

\section{Xiaowei Song ${ }^{1}$, Yongpei Hao ${ }^{2}$ and Xiaodong Zhu ${ }^{1, *}$}

1 State Key Laboratory of Pollution Control and Resources Reuse, School of the Environment, Nanjing University, Nanjing 210023, China; E-Mail: dg1325030@smail.nju.edu.cn

2 School of Geographic and Oceanographic Sciences, Nanjing University, Nanjing 210023, China; E-Mail: dg1427011@smail.nju.edu.cn

* Author to whom correspondence should be addressed; E-Mail: xdzhu@nju.edu.cn; Tel.: +86-25-8359-6675; Fax: +86-25-8368-6734.

Academic Editor: Marc A. Rosen

Received: 4 May 2015 / Accepted: 3 July 2015 / Published: 15 July 2015

\begin{abstract}
Many countries are attempting to reduce energy consumption and $\mathrm{CO}_{2}$ emissions while increasing the productivity and efficiency of their industries. An undesirable-output-oriented data envelopment analysis (DEA) model with slacks-based measure (SBM) was used to evaluate the changes in the environmental efficiency of the transportation sector in 30 Chinese provinces (municipalities and autonomous regions) between 2003 and 2012. The potential for decreasing $\mathrm{CO}_{2}$ emissions and energy saving was also assessed. Transportation was found to be inefficient in most of the provinces and the average environmental efficiency was low (0.45). The overall average efficiency reached a maximum in 2005 and continually decreased until a minimum was reached in 2009; since then, it has increased. In general, transportation is more efficient in eastern than in central or western China. A sensitivity analysis was also carried out on the input and output indicators. Based on these findings, some policies are proposed to improve the environmental efficiency of the transportation sector in China.
\end{abstract}

Keywords: environmental efficiency; transportation sector; undesirable output; SBM-DEA model 


\section{Introduction}

The rapid economic development of China has led to environmental issues being of great concern, and, therefore, the focus of much research. Chinese economic development has, for the past three decades, mainly relied on energy and labor-intensive industries. Energy is mainly produced from coal and other fossil fuels in China, and the high demand for energy from the industrial and transportation sectors means that large amounts of greenhouse gases (one of which is carbon dioxide) are produced. China's Twelfth Five Year Plan for 2011-2015 (State Council of the People's Republic of China (SCPRC), 2011) [1] made the recommendation: Actively respond to global climate change. Take significantly reducing energy consumption intensity and carbon dioxide emission intensity as a binding target, and effectively control greenhouse gas emissions. More and more people are now realizing the importance of reducing energy consumption in order to decrease energy-related emissions and protect the environment. It is therefore essential that some evaluation is made of the environmental efficiencies of different Chinese industries. In particular, air pollution in China has also become more of a problem in recent years, and one reason for this is that exhaust emissions from the transportation sector have been increasing. The transportation sector is the second-largest source of emissions of air pollutants, accounting for $22 \%$ of global $\mathrm{CO}_{2}$ emissions in 2010 (3\% more than in 2009). Almost three-quarters of these emissions were caused by road transportation. It is therefore crucial that the environmental efficiency of the transportation sector is evaluated so that policies can be implemented to ensure that the sector develops in a more rational way than is currently the case.

The remainder of the paper is structured as follows: Section 2 contains a review of the literature relevant to this topic, and the methodology of this study is explained in Section 3. Section 4 contains some results and Section 5 presents the discussion and policy implications. Finally, some conclusions are made in Section 6.

\section{Literature Review}

It has been widely advocated that the environmental efficiencies of all economic activities should be measured to provide quantitative data to use in analyzing and developing environmental policy analysis [2]. The data envelopment analysis (DEA) model is the main method used for measuring environmental efficiency; this model only requires inputs and outputs to be quantified. Charnes et al. [3] first proposed the original Constant Return to Scale Data Envelopment Analysis (CCR-DEA), which is a nonparametric approach that measures the relative efficiency of decision-making units (DMUs) by comparing multiple inputs with a single output. The DEA is used to identify best practices within a set of comparable decision-making units (DMUs), leading to the identification of an "efficient frontier". The CCR model is appropriately referred to as providing a radial projection, in which, specifically, each input is reduced by the same degree of proportionality. Traditional DEA assumes that all the outputs should be maximized for a given input level. However, when undesirable outputs are generated as by-products of desirable outputs, this assumption is no longer appropriate. In recent years, as the process of manufacturing and production has often been accompanied by undesirable outputs, efficiency that includes undesirable outputs is referred to as "environmental" efficiency [4]. Many 
more advanced DEA models have accounted for undesirable outputs in the production process, such modelling approaches being classified into two types: indirect and direct $[4,5]$.

Indirect approaches are based on the translation of original data and the use of traditional DEA models. One method considers the undesirable outputs as inputs [6], but this method is against the true production process. Others add a large scalar or a multiplicative inverse to undesirable output values $[7,8]$, but these methods can alter the efficient frontier, and the ratios of the original data can be destroyed. Scheel [5] suggested separating the desirable and undesirable outputs by giving the undesirable outputs a negative sign, but this approach can only be applied to one undesirable. In another alternative approach, all undesirable outputs are multiplied by -1 and added together with a proper translation vector for the undesirable outputs [9]. However, in many real life applications this transformation of data may not make sense.

Direct approaches imply that the undesirable output data are applied directly into the modification of the DEA model in order to treat the undesirable output appropriately. Previous approaches include Hyperbolic Efficiency (HE) measure [10] and the Directional Distance Function (DDF) model [11], but these are complex and may not provide the best measures of efficiency. Bian [12] extended the additive DEA model introduced by Charnes et al. [13] by taking into account the slack variables. Some more recent methods apply a combination of models in the DEA approach, for example Portela et al. [14] proposed the range directional model, Fukuyama and Weber [15] proposed the directional network slack-based inefficiency model, and Färe et al. [16] proposed a slack-based model using DDF as a framework. More recently, Sueyoshi et al. [17] extended the basic original model of RAM (Range Adjusted Measure) introduced by Cooper et al. [18] to integrate undesirable outputs.

Tone [19] firstly proposed the slack-based measure (SBM) model and Zhou et al. [2] extended it so that it could incorporate undesirable output, by minimizing the ratio of the average undesirable output reduction to the average desirable output increment. This non-radial model is generally treated as a composite index for modeling economic environmental performance. First, compared to radial efficiency measurement, this model provides a higher discriminating power in modeling environmental performance [2]. Second, in the non-radial approach, inputs and outputs are not impelled to improve uniformly [20]. Third, the efficiency indicator for each variable in the process can be identified in order to increase the efficiency of the DMU being studied.

Rather than being based on methodological orientation, much of the literature instead focuses on empirical orientation, using the DEA model to consider undesirable outputs. The focus is mainly on three aspects: the application of various different approaches, the effect of environmental regulation on environmental efficiency, and the sources of pollution caused by different industries. Among the application of approaches discussed in previously, the DDF approach [21,22] and the SBM model [23,24] are the most popular. The effect of environmental regulation on environmental efficiency has two possible outcomes: Telle and Larsson [25] found that environmental regulations hamper productivity growth; however, some authors argue that environmental regulation can increase environmental efficiency [26-28]. Because different industrial sectors emit different types of pollution, different studies tend to focus on different undesirable outputs, such as $\mathrm{SO}_{2}$ in the electrical utility industry [29], $\mathrm{NO}_{\mathrm{x}}$ in the glass industry [30,31], and $\mathrm{CO}_{2}$ in many industries and water pollution in the pulp and paper industry [25].

For the transportation sector, Tongzon [32] used DEA to measure the efficiency of four Australian and twelve international container ports, while Merkert et al. [33] evaluated the important determinants 
of efficiency for 58 passenger airlines. Lin and Hong [34] evaluated the operational performance of 20 major airports around the world using the DEA model. Chang et al. [35] and Chung et al. [36] analyzed the environmental and energy efficiency of China's transportation sector and maximize the energy-saving potential of the transportation sector in China's 30 administrative regions. However, little of this research in the transportation sector considers changes over longer time scales, and contained few analyses of spatial scales.

In the work described herein, we used related inputs index, desirable outputs index and $\mathrm{CO}_{2}$ emissions as undesirable outputs index in the transportation sector in China between 2003 and 2012, in order to establish a CCR-DEA model and a DEA model considering undesirable output using the slacks-based measure (SBM). The models were used to investigate the environmental efficiency of the transportation sector in China. We also determined the potential energy saving that the provinces could have achieved between 2003 and 2012. This study forms a valuable contribution to the literature by using a considering undesirable output SBM-DEA model to assess the environmental efficiency of the Chinese transportation sector and the potential for decreasing the $\mathrm{CO}_{2}$ emissions from it. The temporal and spatial changes in the environmental efficiency of the Chinese transportation sector between 2003 and 2012 have not previously been analyzed in this way; results from this and similar studies could be used directly to inform future transport policy in China and elsewhere.

\section{Materials and Methods}

\subsection{Data Envelopment Analysis}

The DEA model was formulated by A. Charnes, W.W. Cooper, and E. Rhodes in 1978 [3] and is based on Farrell's [37] non-parametric production frontier function. The DEA model uses mathematical programming based on multiple inputs and outputs to estimate the relative efficiency of DMUs. Relative efficiency classifies a DMU as an efficient or inefficient DMU. An efficient DMU has the most appropriate combinations of input and output variables, which constitute the efficiency frontier. The relative position of a DMU with respect to this efficiency frontier is used as a measure of the extent of the efficiency of an inefficient DMU. As the constituents of DMUs change, the degree of relative efficiency can change accordingly. The use of a DEA can avoid subjective human judgments, because it does not require any predetermined functional forms. In addition, the number of evaluated DMUs should be more than twice the total selected number of inputs and outputs; otherwise, the validity and credibility of the results of a study will be severely compromised.

CCR-DEA Model. The basic DEA model is the CCR model introduced by Charnes et al. [3], which was developed to measure production efficiency under constant return to scale (CRS) conditions. The efficiency of a DMU is a comparative measure of how well it actually processes its inputs to achieve its outputs. The model presumes that $D M U_{j}(j=1, \ldots, n)$ uses input $X_{i j}(i=1, \ldots, m)$, and produces output $Y_{r j}(r=1, \ldots, s)$. The relative efficiency value of $D M U_{j}$ can then be obtained as follows:

Maximize

$$
h_{j}=\frac{\sum_{r=1}^{s} u_{r} Y_{r j}}{\sum_{i=1}^{m} v_{i} X_{i j}}
$$

Subject to: 


$$
\begin{gathered}
\frac{\sum_{r=1}^{s} u_{r} Y_{r j}}{\sum_{i=1}^{m} v_{i} X_{i j}} \leq 1, j=1, \ldots, n \\
u_{r}, v_{i}, \geq \varepsilon \geq 0, r=1, \ldots, s, i=1, \ldots, m
\end{gathered}
$$

where $h_{j}$ is the efficiency value given to unit $n ; u_{r}$ and $v_{i}$ denote the input and output weights, respectively; $\varepsilon$ represents the extremely small positive number (set as $10^{-6}$ ) required to make all $u_{r}, v_{i}$ positive.

SBM model considering undesirable outputs: We suppose that there are $n$ decision-making units (DMUs), expressed as $D M U_{j}(j=1,2, \ldots, n) . X$ and $Y$ are the input and output variables, respectively, and $m, s_{1}$ and $s_{2}$ are the numbers of inputs, desirable outputs, and undesirable output variables, respectively. $s_{i}$ is the slack variable, representing excess input. Each DMU has $m$ types of inputs $X_{i j}(i=1,2, \ldots, m), s_{1}$ types of desirable output $Y_{i j}\left(i=1,2, \ldots, s_{1}\right)$, and $s_{2}$ types of undesirable output $C_{i j}\left(i=1,2, \ldots, s_{2}\right)$, so the vectors for the inputs, desirable outputs and undesirable outputs can be expressed as $X \in R^{m}, Y \in R^{s 1}$, and $C \in R^{s 2}$, respectively. The matrices $X, Y$, and $C$ are defined below.

$$
\begin{gathered}
X=\left[x_{1}, \cdots, x_{n}\right] \in R^{m \times n} ; Y=\left[y_{1}, \cdots, y_{n}\right] \in R^{s_{1} \times n} ; C=\left[c_{1}, \cdots, \mathrm{c}_{n}\right] \in R^{s_{2} \times n} ; \\
X>0, Y>0 \text { and } C>0
\end{gathered}
$$

The production possibility set $P$ under constant returns to scale is defined below.

$$
P=\{(x, y, \mathrm{c}) \mid x \geq X \lambda, y \leq Y \lambda, \mathrm{c} \geq C \lambda, \lambda \geq 0\}
$$

According to Tone $(2001,2004)$ [19,38], the undesirable outputs SBM-DEA model can be expressed as shown in Equation (2).

$$
\rho_{0}^{*}=\min \frac{1-\frac{1}{m} \sum_{i=1}^{m} \frac{s_{i 0}^{\mathrm{x}}}{x_{i 0}}}{1+\frac{1}{s_{1}+s_{2}}\left[\sum_{r=1}^{s_{1}} \frac{s_{r 0}^{\mathrm{y}}}{y_{r 0}}+\sum_{r=1}^{s_{2}} \frac{s_{r 0}^{c}}{c_{r 0}}\right]}
$$

S.T. $x_{0}=X \lambda+s_{0}^{-} ; y_{o}=Y \lambda-s_{0}^{y} ; \mathrm{c}_{0}=C \lambda+s_{0}^{c} ; s_{0}^{-} \geq 0, s_{0}^{y} \geq 0, s_{0}^{c} \geq 0, \lambda \geq 0$

where $s_{0}^{-}$and $s_{0}^{c}$ are the slacks in the inputs and outputs, respectively, and $\lambda$ is the weight vector. A particular decision-making unit is efficient if and only if $\rho^{*}=1$, i.e., when $s^{-}=0, s^{y}=0, s^{c}=0$. If $\rho^{*}<1$, which indicates that the evaluation unit is inefficient, it is necessary to optimize the inputs, desirable outputs, and undesirable outputs to improve the environmental efficiency value.

The slack variable $S_{0}^{c}$ is the excess of carbon emissions, and, in this study, it was used to estimate the potential for decreasing the carbon emissions in each province.

\subsection{Indicator Selection and Data Sources}

This paper examines 30 provinces, autonomous regions, and municipalities in mainland China, excluding Tibet, due to the lack of relevant energy data. Considering that this research focused on the regional transportation sector in China, three factors were selected as the inputs and two factors as the outputs.

Inputs. The basic principles of economics suggest labor and capital as the two main inputs. Thus, the amount of labor employed and the amount of fixed capital investment were used as the non-energy 
input values, and the volume of energy consumed in the transportation sector was used as the energy input value. Almost all the literature on energy or environmental efficiency measurement uses these three inputs [39]. Because capital stock data are not available, assuming the case of a constant depreciation rate, changes in investment can closely convey changes in capital stock [40]. We used the amount of fixed capital investment to represent capital stock input, common with other authors $[41,42]$. Even though it is a commonly recommended proxy for cases where data are unavailable, there are also some limitations to this approach because fixed capital investment can differ from true capital input.

The outputs can be divided into desirable and undesirable.

Desirable outputs. The desirable outputs select the amount of added value from the transportation sector based on current prices. The desirable output used in this paper was "Gross Domestic Product by transportation sector", because GDP is a value added concept. The China Statistical Year book considers the "Gross Domestic Product by transportation sector" to be the "value-added of transportation sector"; furthermore, we checked and found the values of these two items were the same. In fact, GDP has many of the same characteristics as revenue, and we therefore used the added value amount as an output, in common with other authors [35].

Undesirable outputs. $\mathrm{CO}_{2}$ emissions related to the fuel consumed in the transportation sector were treated as undesirable outputs. Data for the consumption of different fuels by the transportation sector were taken from the Chinese Energy Statistics Year Books for 2004-2013.

Following the guidelines developed by the Intergovernmental Panel on Climate Change (IPCC, 2006) [43] for building National Greenhouse Gas Inventories (Volume 2 and Equation (2.2), we estimated $\mathrm{CO}_{2}$ emissions from the combustion of different fossil fuels using Equation (3).

$$
\mathrm{CO}_{2} \text { emission }=\sum_{i=1}^{n} A \times C C F_{i} \times H E_{i} \times C O F_{i} \times(44 / 12)
$$

Table 1 shows the data for $\mathrm{CO}_{2}$ emissions, which are related to the total amount of carbonaceous fuel combusted $(A)$, the carbon content factor $(C C F)$, the heat equivalent $(H E)$, and the carbon oxidation factor $(C O F)$ of the fuel concerned. The $\mathrm{CO}_{2}$ emission factor (CEF) of each fuel is given by the quantity $\left\{C C F_{i} \times H E_{i} \times C O F_{i} \times(44 / 12)\right\}$, where the number $(44 / 12)$ represents the ratio of the molecular of $\mathrm{CO}_{2}$ and carbon.

Table 1. $\mathrm{CO}_{2}$ emission factors by major carbonaceous fuel in China.

\begin{tabular}{ccccccc}
\hline Fuels & Coal & Petrol & Kerosene & Diesel & Fuel oil & Nature gas \\
\hline $\mathrm{CCF}^{\mathrm{a}}$ & 27.28 & 18.9 & 19.6 & 20.17 & 21.09 & 15.32 \\
$\mathrm{HE}^{\mathrm{a}}$ & 192.14 & 448 & 447.5 & 433.3 & 401.9 & 0.384 \\
$\mathrm{COF}(\%)$ & 92.3 & 98 & 98.6 & 98.2 & 98.5 & 99.0 \\
\hline
\end{tabular}

a $\mathrm{CCF}$ and $\mathrm{HE}$ are expressed in tons of carbon per trillion Joules, and trillion Joules per $10^{4}$ tons $\left(\mathrm{m}^{3}\right)$, respectively. Source: NDRC, 2007 [44]. 


\section{Results}

Table 2 shows the descriptive statistics for the input and output variables. The average investment in the Chinese provincial transportation sector between 2003 and 2012 was 51 billion yuan, and the sector employed 210,000 people, consumed $7 \times 10^{6}$ tons of standard coal equivalent of energy, produced 56 billion yuan in added value, and emitted $20 \times 10^{6}$ tons of $\mathrm{CO}_{2}$. The standard deviations shown in Table 2 show that the variations in the energy inputs and $\mathrm{CO}_{2}$ emissions were much greater than the variations in the labor used, the added value, and the capital invested.

Table 2. Descriptive statistics of the input and output variables.

\begin{tabular}{ccccccc}
\hline Inputs and Outputs & Variable & Unit & Mean & Max & Min & Std. Dev. \\
\hline \multirow{2}{*}{ Non-energy input } & Labor & $10^{3}$ persons & 210.24 & 618.48 & 28 & 116.88 \\
& Capital & $10^{9}$ yuan & 51.46 & 208.66 & 2.92 & 39.60 \\
Energy input & Energy & $10^{3}$ TCEs & 7332.58 & $30,239.77$ & 270.54 & 5605.03 \\
Desirable output & Added Value & $10^{9}$ yuan & 56.91 & 251.62 & 2.78 & 46.99 \\
Undesirable output & $\mathrm{CO}_{2}$ emissions & $10^{3}$ tons & 20,050 & $89,159.66$ & 638.03 & $16,027.66$ \\
\hline
\end{tabular}

$\mathrm{TCE}=$ ton of standard coal equivalent.

$\mathrm{CO}_{2}$ emissions. The $\mathrm{CO}_{2}$ emissions produced by the transportation sectors in the different provinces were calculated using Equation (3). The mean $\mathrm{CO}_{2}$ emissions produced by the Chinese transportation sector between 2003 and 2012 are shown in Figure 1. It can be seen from the figure that more $\mathrm{CO}_{2}$ emissions were produced in Guangdong and Shandong provinces (more than $50 \times 10^{6}$ tons in each) than in the other provinces, and that Qinghai province emitted the least $\mathrm{CO}_{2}$.

Thousands Tons

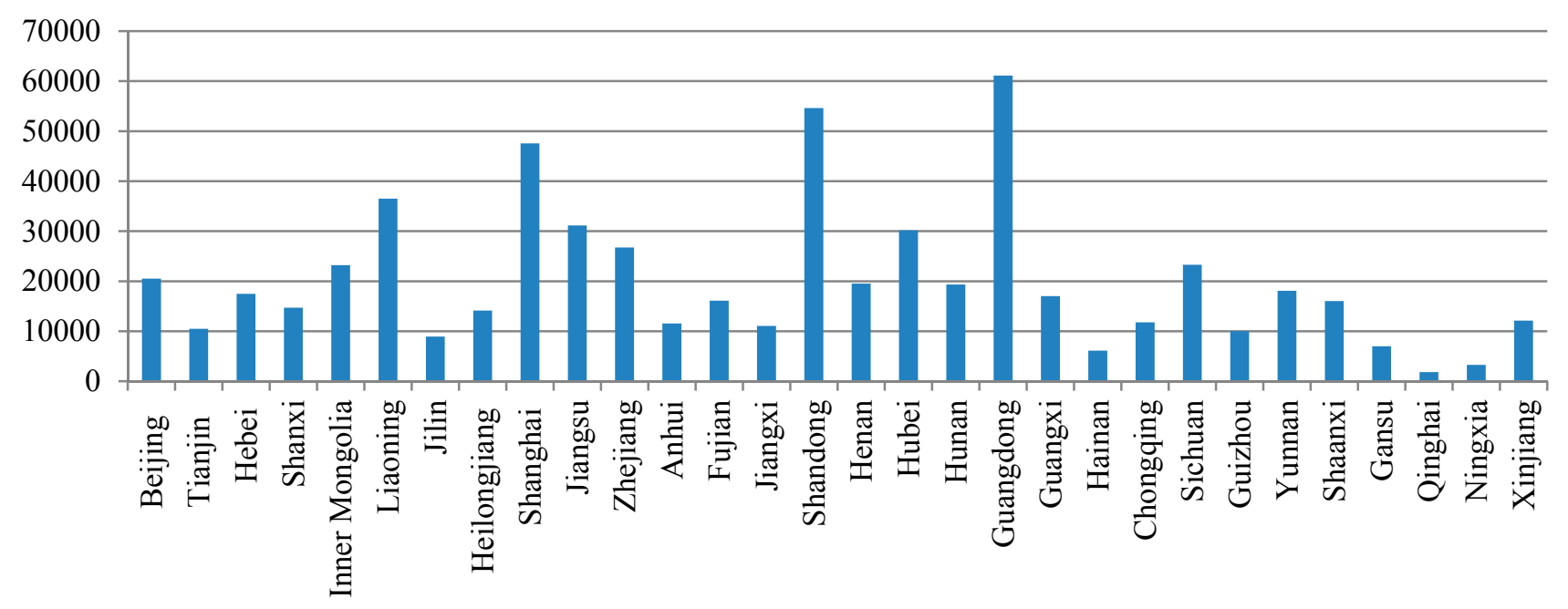

Figure 1. Mean $\mathrm{CO}_{2}$ emissions from the transportation sectors in different Chinese provinces between 2003 and 2012. 
Environmental efficiency in the transportation sector in the different provinces. Table A1 (see Appendix) and Figures 2 and 3 show the results of the environmental efficiency for the transportation sector, calculated using both the CCR model and the SBM model considering undesirable output. The average value produced by the CCR model for the 30 provinces between 2003 and 2012 was 0.64 , while the average value from the SBM model considering undesirable output was only 0.45 . As mentioned above, the SBM model considering undesirable output is better able to reflect the real level of environmental efficiency. The results show that environmental pollution has led to a greater loss of efficiency, which implies that any efficiency evaluation is meaningless if environmental factors are not considered. It furthermore proves that the efficiency evaluation using the SBM model considering undesirable outputs can avoid the angular and radial defects of the traditional DEA model and can improve the accuracy and reliability of the efficiency evaluation. The SBM model results show that the environmental efficiency of the Chinese transportation sector was poor between 2003 and 2012. The highest environmental efficiency for the transportation sector was in Hebei Province, which lay at the efficiency frontier during this period. Hebei Province has good environmental quality standards in its transportation sector, its emissions are controlled reasonably well, and its environmental policies are forcing continual improvement in this regard.

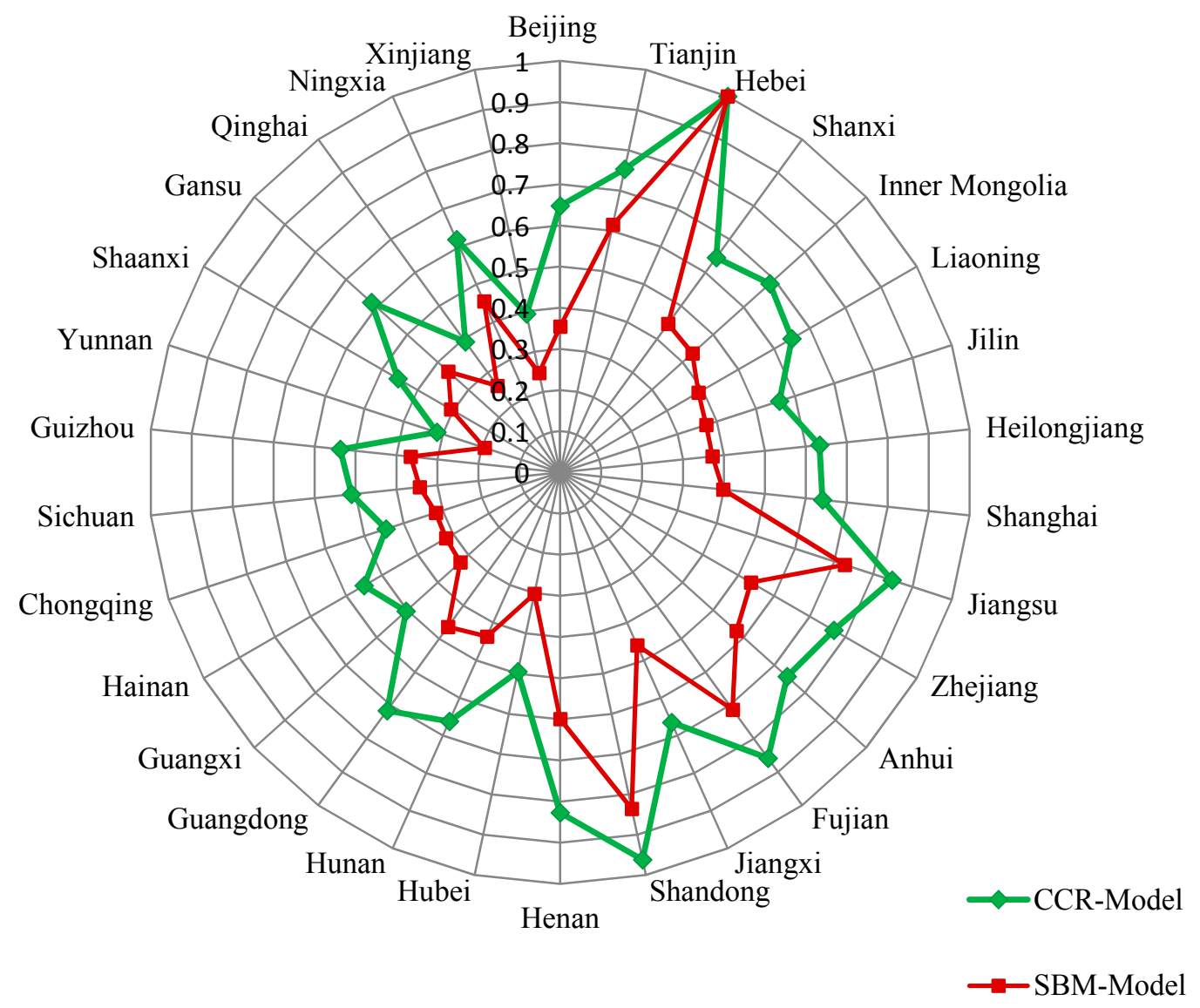

Figure 2. Average environmental efficiency values for the transportation sector in 30 Chinese provinces between 2003 and 2012. 


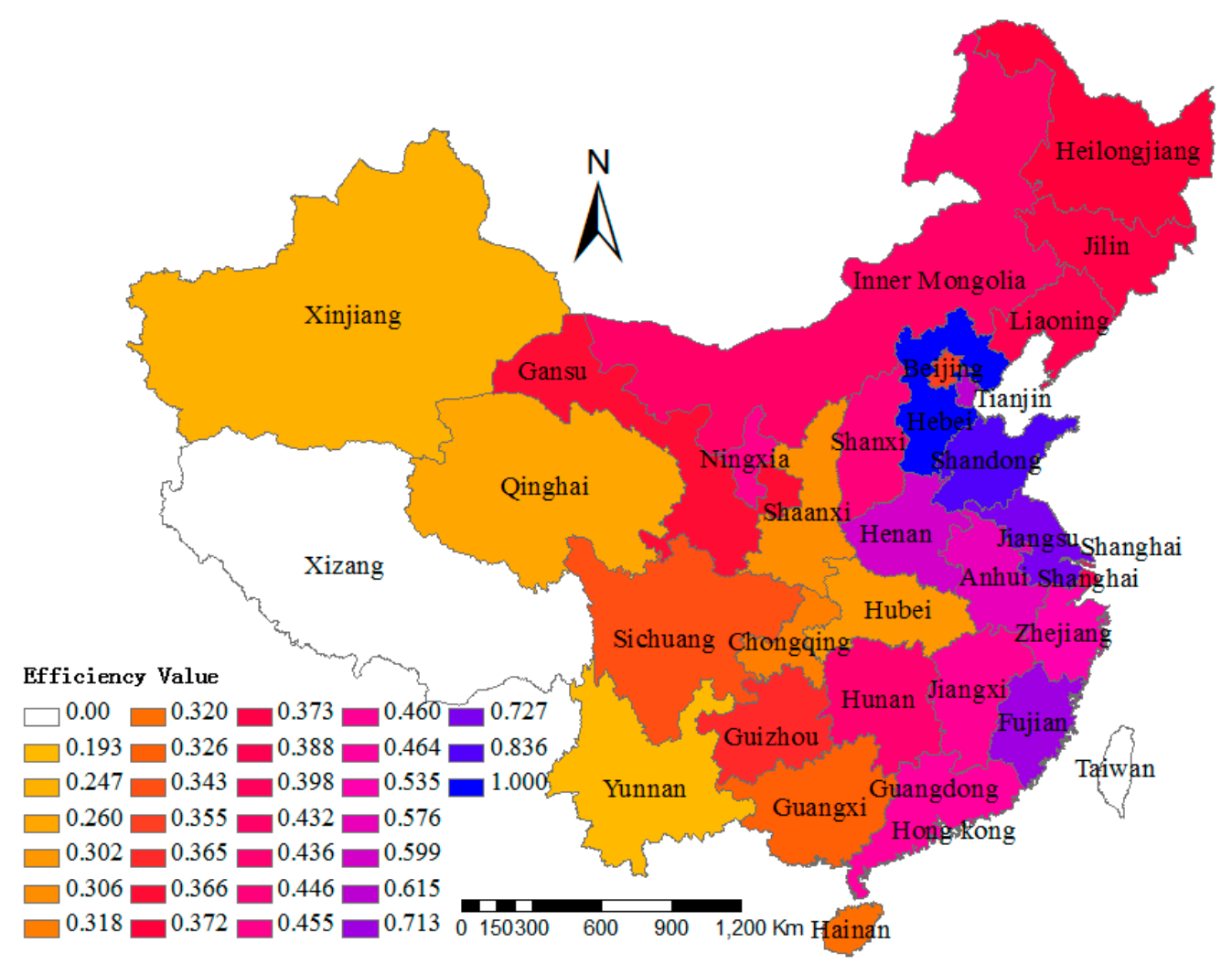

Figure 3. Mean environmental efficiency values for the transportation sector in 30 Chinese provinces between 2003 and 2012.

The average environmental efficiency values for the transportation sectors in Shandong, Jiangsu and Fujian provinces were $0.84,0.73$, and 0.7 respectively, and these were at the efficiency frontier in some years. However, the trends in environmental efficiency for these provinces differed somewhat. It is noteworthy that the environmental efficiency in Shandong Province began to decrease in 2010. The environmental efficiency of Jiangsu Province increased consistently throughout the study period, whereas the environmental efficiency of Fujian Province followed the opposite trend. Appropriate measures need to be taken to improve the environmental efficiency of the transportation sector in Fujian Province, and to restore the previously high levels of environmental efficiency seen in the transportation sector in this province.

The average environmental efficiency value for the transportation sectors in Tianjin, Zhejiang, Anhui and Henan provinces lies between 0.5 and 0.7 , which is in the middle of the range for all the Chinese provinces. The average environmental efficiency values for the transportation sectors of the other 22 provinces is below 0.5, with the lowest value (0.19) being found for Yunnan Province. This indicates that the transportation sectors in most Chinese provinces are very inefficient, and there is much scope for improving environmental controls, policies and energy utilization technologies in most parts of China.

The above analysis shows that the transportation sectors in most Chinese provinces are not performing in environmentally efficient ways, because they require such massive increase in inputs of resources in order to increase their outputs. Environmental efficiency levels of less than $50 \%$ of the 
ideal or target level were found for most provinces, leading us to conclude that the Chinese transportation sector as a whole is very inefficient in environmental terms.

Changes in the environmental efficiency trends in the transportation sector. As shown in Figure 4, the environmental efficiency trends in the Chinese transportation sector generally followed three stages. The environmental efficiency value decreased from 2005, reaching a minimum in 2009, before increasing slightly after 2009. The highest average environmental efficiency value between 2003 and 2012 was 0.57 and the lowest value was just 0.40 . In addition, from Figure 5, it can be seen that $\mathrm{CO}_{2}$ emissions increased in line with energy consumption, except in 2010 , when $\mathrm{CO}_{2}$ emissions dramatically decreased. The environmental efficiency value therefore significantly increased in 2010.



Figure 4. Regional differences in the transportation sector in terms of the environmental efficiency value.

Regional differences in the environmental efficiency of the transportation sector. There were some obvious differences between the environmental efficiencies of the transportation sectors in the different Chinese provinces. To make the results relevant to the policymaking process, we refer to the "three belts" scheme of the Seventh Five-Year Plan (1986-1990) to classify the three areas in China, namely eastern, western, and central. The average GDPs of Inner Mongolia and Guizhou Province during the study period were both lower than the average GDP of the western area, so Inner Mongolia and Guizhou Province were classified as the Western area. The 30 provinces, municipalities, and autonomous regions were classified as follows. The eastern area included Beijing, Tianjin, Hebei, Liaoning, Shanghai, Jiangsu, Zhejiang, Fujian, Shandong, Guangdong, and Hainan. The central area included Shanxi, Jilin, Heilongjiang, Anhui, Jiangxi, Henan, Hubei, and Hunan. The western area included Inner Mongolia, Guangxi, Chongqing, Sichuan, Guizhou, Yunnan, Shaanxi, Gansu, Qinghai, Ningxia, and Xinjiang. In terms of their general characteristics (1) the eastern area has a higher economic growth rate and receives more direct foreign investment than most parts of the central and western areas; (2) the central area is largely agricultural and has a high population density; (3) the western area is the least developed area and has a comparatively low population density.

Figure 4 also shows the trends in the environmental efficiencies of the transportation sectors in the three areas. The efficiency value was highest for the eastern and lowest for the western area. However, from Figure 5, it can be seen that although the western area produced higher $\mathrm{CO}_{2}$ emissions in more recent years, it also had higher fixed capital investments and added value thanks to the scale of the development that took place in the western area, together with the westward migration of eastern enterprises. The differences between the areas in all these indices have therefore gradually been reducing. 

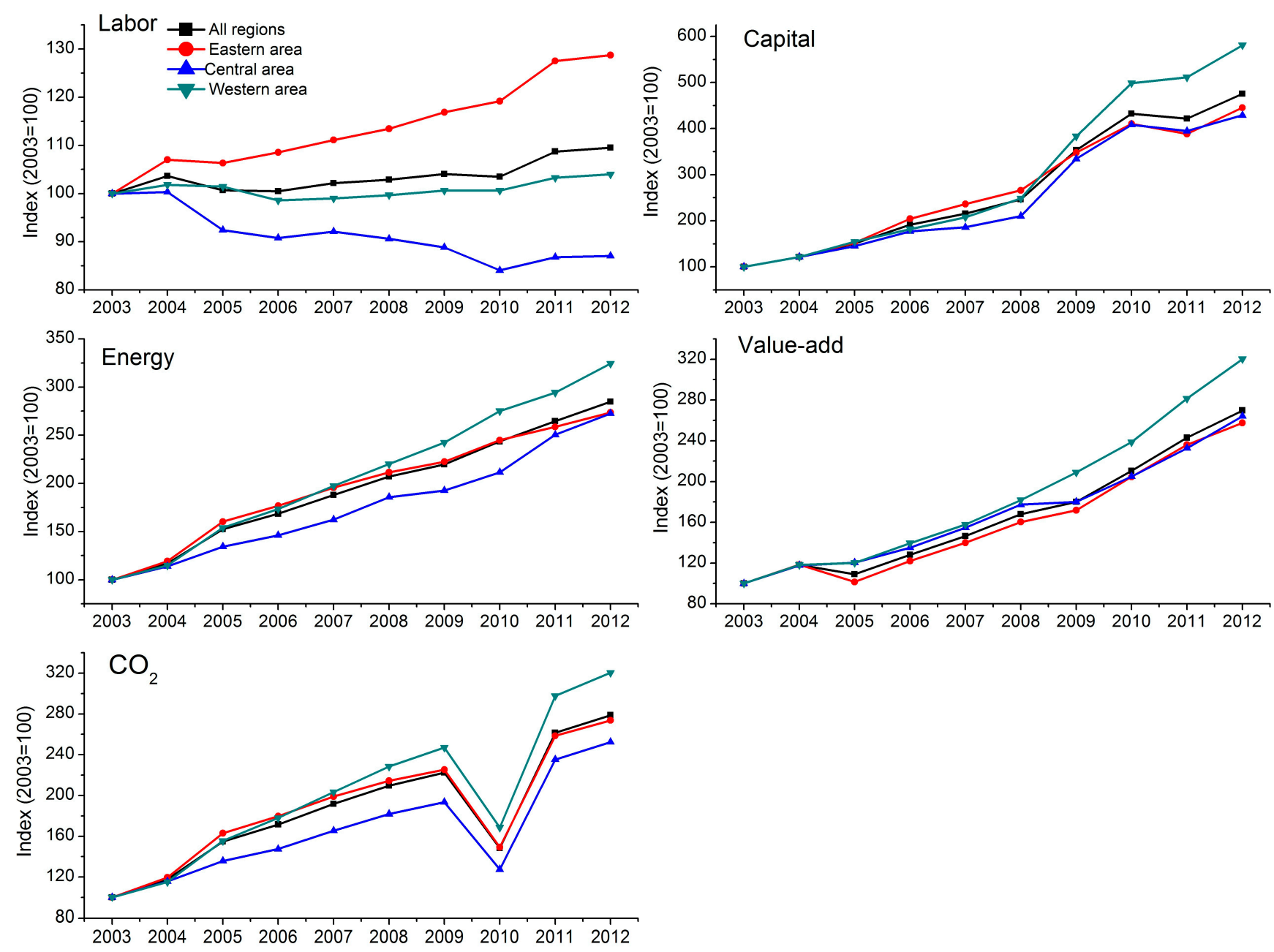

Figure 5. Index changes of inputs and outputs for the all regions, eastern area, central area, and western area.

Sensitivity analysis. In order to study the influence of each input and output indicators on the efficiency value, we applied sensitivity analysis. By changing the number of input and output indicators, we could explain the degree to which environmental efficiency is affected by the input and output indicators in each case. The results are shown in Table 3.

Table 3. The results of sensitivity analysis.

\begin{tabular}{ccccccccc}
\hline & \multicolumn{3}{c}{ CCR } & & \multicolumn{3}{c}{ SBM } \\
\cline { 2 - 8 } Provinces & No Labor & No Capital & No Energy & No Labor & No Capital & No Energy & No CO2 \\
\hline Beijing & 0.00 & -0.34 & -0.07 & -0.10 & -0.14 & 0.04 & 0.35 \\
Tianjin & 0.00 & -0.04 & -0.05 & 0.00 & -0.02 & 0.00 & 0.15 \\
Hebei & 0.00 & 0.00 & 0.00 & 0.00 & 0.00 & 0.00 & 0.00 \\
Shanxi & 0.00 & -0.12 & -0.04 & 0.00 & -0.04 & 0.02 & 0.17 \\
Inner Mongolia & -0.17 & 0.00 & 0.00 & -0.06 & -0.04 & 0.10 & 0.22 \\
Liaoning & -0.01 & -0.27 & 0.00 & -0.03 & -0.12 & 0.08 & 0.32 \\
Jilin & 0.00 & -0.16 & -0.03 & 0.00 & -0.06 & 0.02 & 0.20 \\
Heilongjiang & 0.00 & -0.38 & -0.02 & 0.00 & -0.13 & 0.06 & 0.33 \\
Shanghai & 0.00 & -0.74 & 0.00 & 0.00 & -0.84 & 0.00 & 0.00 \\
\hline
\end{tabular}


Table 3. Cont.

\begin{tabular}{|c|c|c|c|c|c|c|c|}
\hline \multirow{2}{*}{ Provinces } & \multicolumn{3}{|c|}{ CCR } & \multicolumn{4}{|c|}{ SBM } \\
\hline & No Labor & No Capital & No Energy & No Labor & No Capital & No Energy & $\mathrm{No} \mathrm{CO}_{2}$ \\
\hline Jiangsu & 0.00 & -0.16 & 0.00 & 0.00 & -0.39 & 0.00 & 0.00 \\
\hline Zhejiang & 0.00 & -0.12 & -0.03 & 0.00 & -0.05 & 0.04 & 0.20 \\
\hline Anhui & 0.00 & -0.21 & 0.00 & -0.03 & -0.10 & 0.07 & 0.26 \\
\hline Fujian & -0.09 & 0.00 & 0.00 & -0.03 & -0.02 & 0.01 & 0.18 \\
\hline Jiangxi & 0.00 & -0.27 & -0.03 & -0.05 & -0.10 & 0.05 & 0.28 \\
\hline Shandong & -0.04 & -0.16 & 0.00 & -0.02 & -0.16 & 0.12 & 0.33 \\
\hline Henan & 0.00 & -0.31 & -0.01 & 0.00 & -0.12 & 0.07 & 0.30 \\
\hline Hubei & -0.03 & -0.05 & 0.00 & -0.01 & -0.04 & 0.05 & 0.18 \\
\hline Hunan & 0.00 & -0.10 & -0.02 & 0.00 & -0.05 & 0.04 & 0.18 \\
\hline Guangdong & 0.00 & -0.37 & 0.00 & -0.06 & -0.14 & 0.08 & 0.35 \\
\hline Guangxi & 0.00 & -0.06 & -0.01 & 0.00 & -0.03 & 0.03 & 0.15 \\
\hline Hainan & -0.02 & -0.21 & 0.00 & -0.02 & -0.09 & 0.07 & 0.27 \\
\hline Chongqing & 0.00 & -0.04 & 0.00 & 0.00 & -0.02 & 0.02 & 0.13 \\
\hline Sichuan & -0.09 & 0.00 & 0.00 & -0.02 & -0.01 & 0.01 & 0.14 \\
\hline Guizhou & -0.24 & 0.00 & 0.00 & -0.07 & -0.00 & 0.07 & 0.34 \\
\hline Yunnan & -0.02 & -0.01 & 0.00 & -0.01 & -0.02 & 0.02 & 0.09 \\
\hline Shaanxi & 0.00 & -0.08 & 0.00 & 0.00 & -0.05 & 0.04 & 0.17 \\
\hline Gansu & 0.00 & -0.26 & -0.02 & 0.00 & -0.10 & 0.05 & 0.26 \\
\hline Qinghai & 0.00 & 0.00 & -0.01 & 0.00 & -0.01 & 0.01 & 0.08 \\
\hline Ningxia & 0.00 & -0.40 & 0.00 & 0.00 & -0.56 & 0.00 & 0.00 \\
\hline Xinjiang & 0.00 & -0.16 & 0.00 & 0.00 & -0.07 & 0.05 & 0.20 \\
\hline
\end{tabular}

Due to the particular nature of the undesirable output, the sensitivity analysis was also divided into two parts in the calculation. Because there is only one desirable output in this study, the sensitivity analysis did not consider the sensitivity in respect to the desirable output. We only use the data for 2012 as a representative sample of all years.

If we do not consider the undesirable output, in general, three input indicators all have an influence on the environmental efficiency value. If the labor and energy indicators are removed, the efficiency value changes are somewhat lower; the labor indicator only has a notable impact in Inner Mongolia, Guizhou, Fujian, Sichuan, and the influence of energy indicator is only slight; the efficiency value of most provinces decreases, but the changes are less than 0.1. Capital has the greatest effect on the environmental efficiency value. There are in fact 24 provinces in which the efficiency values decreases, with the eastern provinces showing the most obvious change. The reason for the higher value of efficiency in the eastern provinces is related to the large capital investment there.

If we do consider the undesirable output, the changes in the efficiency value are similar when removing the labor and energy indicators. However, the dependence of the energy indicator on the undesirable output indicator has an opposite trend, which is that the efficiency values increase rather than decrease, and this is due to the particularity of the indicators. Reducing the energy input and undesirable output can cause the efficiency value to increase, suggesting that the influence of the undesirable output is higher than that of the energy indicator. The provinces where the energy indicator 
has a greater influence on the efficiency value are Inner Mongolia, Liaoning, Guangdong, Anhui, Hainan and Guizhou, indicating that the energy utilization of these provinces are unreasonable. The undesirable output has a notable influence on the efficiency values in all provinces, and the reductions in the efficiency value are greater than 0.3 , indicating that these provinces need to reduce their undesirable outputs.

Analysis of the potential for decreasing $\mathrm{CO}_{2}$ emissions. Table 4 shows the potential for decreasing $\mathrm{CO}_{2}$ emissions in the transportation sectors of the provinces between 2003 and 2012. Of the less efficient provinces, Guangdong had the greatest potential for decreasing its carbon emissions $\left(393.78 \times 10^{6}\right.$ tons less carbon could have been released than was released between 2003 and 2012), and Qinghai had the least potential for decreasing carbon emissions $\left(11.84 \times 10^{6}\right.$ tons less carbon could have been released than was released between 2003 and 2012). In addition, carbon emissions from the transportation sectors in China as a whole could have been reduced by $3291 \times 10^{6}$ tons between 2003 and 2012. This implies that there is a great deal of scope for decreasing the carbon emissions from the Chinese transportation sector, giving cause for some optimism for the Chinese government, which aspires to decrease its carbon emissions and to develop a more environmentally friendly society.

Table 4. Potential decrease in carbon emissions from the transportation sector in each province $\left(10^{6}\right.$ tons $)$.

\begin{tabular}{ccccccccccc}
\hline & $\mathbf{2 0 0 3}$ & $\mathbf{2 0 0 4}$ & $\mathbf{2 0 0 5}$ & $\mathbf{2 0 0 6}$ & $\mathbf{2 0 0 7}$ & $\mathbf{2 0 0 8}$ & $\mathbf{2 0 0 9}$ & $\mathbf{2 0 1 0}$ & $\mathbf{2 0 1 1}$ & $\mathbf{2 0 1 2}$ \\
\hline Beijing & 8.08 & 9.59 & 3.56 & 8.60 & 11.64 & 15.25 & 16.82 & 20.67 & 14.24 & 19.08 \\
Tianjin & 0.00 & 0.00 & 3.69 & 4.94 & 4.62 & 5.80 & 5.46 & 2.80 & 5.58 & 6.08 \\
Hebei & 0.00 & 0.00 & 0.00 & 0.00 & 0.00 & 0.00 & 0.00 & 0.00 & 0.00 & 0.00 \\
Shanxi & 4.62 & 4.83 & 1.02 & 2.11 & 2.09 & 14.34 & 15.33 & 8.18 & 12.28 & 12.86 \\
Inner Mongolia & 1.72 & 5.13 & 8.25 & 12.33 & 14.97 & 17.57 & 20.60 & 14.80 & 24.93 & 27.58 \\
Liaoning & 12.76 & 10.33 & 19.89 & 25.84 & 29.69 & 29.31 & 32.12 & 20.53 & 38.26 & 41.84 \\
Jilin & 2.23 & 1.43 & 0.59 & 2.37 & 5.58 & 6.63 & 7.24 & 5.48 & 7.99 & 8.81 \\
Heilongjiang & 7.06 & 6.05 & 3.08 & 7.63 & 8.04 & 5.93 & 8.77 & 5.17 & 15.28 & 17.70 \\
Shanghai & 19.91 & 26.77 & 26.13 & 35.19 & 42.51 & 44.64 & 49.36 & 26.37 & 42.49 & 0.00 \\
Jiangsu & 12.19 & 13.28 & 6.65 & 9.35 & 12.06 & 14.94 & 16.71 & 0.00 & 0.00 & 0.00 \\
Zhejiang & 4.89 & 0.00 & 9.02 & 13.07 & 15.22 & 17.38 & 19.51 & 10.83 & 21.91 & 24.03 \\
Anhui & 4.30 & 3.69 & 0.00 & 1.72 & 3.52 & 3.35 & 6.24 & 4.29 & 8.46 & 15.51 \\
Fujian & 0.00 & 0.00 & 0.00 & 2.12 & 2.82 & 7.21 & 10.49 & 6.21 & 12.88 & 13.21 \\
Jiangxi & 7.99 & 5.92 & 2.01 & 4.28 & 4.61 & 4.49 & 5.67 & 3.98 & 8.13 & 7.83 \\
Shandong & 12.27 & 2.29 & 0.00 & 0.00 & 0.00 & 0.00 & 0.00 & 17.34 & 39.86 & 52.77 \\
Henan & 1.54 & 6.63 & 0.00 & 2.09 & 4.56 & 2.46 & 12.30 & 8.27 & 18.26 & 20.28 \\
Hubei & 15.23 & 13.84 & 17.29 & 20.22 & 22.85 & 27.14 & 25.96 & 16.65 & 28.81 & 29.58 \\
Hunan & 9.90 & 10.13 & 7.85 & 10.52 & 12.41 & 9.06 & 12.86 & 8.90 & 16.48 & 13.15 \\
Guangdong & 15.97 & 23.41 & 31.17 & 36.44 & 42.33 & 47.28 & 51.35 & 31.90 & 55.63 & 58.30 \\
Guangxi & 5.88 & 8.08 & 7.80 & 10.83 & 12.36 & 12.33 & 15.34 & 9.03 & 16.93 & 19.05 \\
Hainan & 2.94 & 2.84 & 1.65 & 3.20 & 3.53 & 5.76 & 7.09 & 4.38 & 7.84 & 7.89 \\
Chongqing & 2.51 & 7.19 & 3.85 & 5.21 & 8.10 & 9.58 & 8.46 & 6.61 & 11.23 & 13.03 \\
Sichuan & 9.25 & 8.25 & 6.23 & 10.34 & 14.08 & 18.07 & 24.85 & 15.83 & 26.95 & 26.49 \\
Guizhou & 3.10 & 3.82 & 3.22 & 5.03 & 6.52 & 9.32 & 7.06 & 4.46 & 8.62 & 11.13 \\
\hline & & & & & & & & & &
\end{tabular}


Table 4. Cont.

\begin{tabular}{ccccccccccc}
\hline & $\mathbf{2 0 0 3}$ & $\mathbf{2 0 0 4}$ & $\mathbf{2 0 0 5}$ & $\mathbf{2 0 0 6}$ & $\mathbf{2 0 0 7}$ & $\mathbf{2 0 0 8}$ & $\mathbf{2 0 0 9}$ & $\mathbf{2 0 1 0}$ & $\mathbf{2 0 1 1}$ & $\mathbf{2 0 1 2}$ \\
\hline Yunnan & 8.67 & 1.91 & 11.61 & 14.47 & 15.91 & 16.43 & 18.09 & 13.12 & 24.75 & 26.54 \\
Shaanxi & 5.87 & 5.78 & 5.49 & 6.69 & 8.86 & 12.26 & 15.99 & 10.89 & 18.52 & 18.87 \\
Gansu & 4.96 & 4.77 & 2.86 & 3.35 & 2.79 & 3.67 & 4.52 & 3.41 & 5.29 & 6.36 \\
Qinghai & 0.42 & 0.18 & 0.00 & 0.21 & 1.18 & 1.65 & 2.01 & 1.44 & 2.34 & 2.41 \\
Ningxia & 2.88 & 0.74 & 1.93 & 2.62 & 2.83 & 2.82 & 1.92 & 1.24 & 0.78 & 0.00 \\
Xinjiang & 5.25 & 9.96 & 6.50 & 9.00 & 9.60 & 10.03 & 9.84 & 6.93 & 11.71 & 12.90 \\
\hline
\end{tabular}

Potential energy saving in the transportation sector in China. According to the DEA theory, overall, technically inefficient DMUs can become efficient and reach a required benchmark through slack and radial adjustment. Figure 6 show the potential energy saving in transportation sectors of the different regions. In four regions the potential energy saving was more than 60 Mtce during the period of interest. Guangdong had the greatest potential energy saving, followed by Shanghai, Liaoning, and Hubei, in that order. Qinghai had the lowest potential energy saving of all the energy-inefficient regions, while the potential energy saving of Hebei was zero. Although Yunnan had the lowest average environmental efficiency (0.19), it did not have the greatest potential energy saving. The average environmental efficiency of Shandong was 0.62 , but there are six provinces (Guangdong, Shanghai, Liaoning, Hubei, Inner Mongolia and Sichuan) whose potential energy saving was larger than that of Yunnan. The reason for this finding is the energy consumption in these provinces. These six provinces consume a large amount of energy in their transportation sectors, at 195 Mtce, 214 Mtce, 165 Mtce, 131 Mtce, 113 Mtce and 91, 86 Mtce, respectively, but Yunnan had a smaller energy consumption of 64 Mtce over the period.



Figure 6. Potential energy saving for the transportation sector in China by province. 


\section{Discussion and Policy Implications}

\subsection{Discussion}

The increasing focus on sustainable development has led to "environmental efficiency" being advocated widely by those involved in environmental policy analysis and decision-making. In fact, improving environmental efficiency has been considered the most effective way of decreasing carbon dioxide emissions and increasing the potential benefits. The transportation sector has become a major energy consumer and producer of environmental pollution. From the above analysis, we know that the Hebei lies on the efficiency frontier and should therefore serve as a model for other regions, allowing them to improve their environmental efficiency in the transportation sector. Yunnan shows a low efficiency in the transportation sector, and measures must be taken to improve its efficiency as soon as possible.

Different environmental efficiency values were found for different areas of China. In general, provinces located in the east show relatively high efficiency values because the eastern area is more developed than most of the central and western areas, and it also has a higher population density, better transport infrastructure, and is where more goods are transported. This implies that more economically active provinces have relatively high environmental efficiency values. Some of the provinces in the west of China show low environmental efficiency values, but so do some of the more developed provinces of the east (including Beijing and Shanghai). Beijing, the capital of China, is a huge city with an excellent road transport system. However, there were more than five million vehicles in Beijing in 2010, and it has been described as one of the most congested cities in the world. The transportation system in Beijing has a very clear influence on the environment, in that atmospheric haze caused by emissions from the transportation sector has become a matter of great concern.

The trend in the environmental efficiency of the Chinese transportation sector is related to the effects of the 2008 financial crisis and policy guidance contained in the Eleventh Five-Year Plan (2006-2010). The policy is to reverse the increasing energy consumption of the Chinese transportation sector; efforts should increasingly be made to conserve energy and protect the environment. A series of new transportation policies has been implemented, and the environmental efficiency of the transportation sector has been increasing continually since 2009. Regarding the modes of transport used, rail transport is considered the most environmentally benign form of transportation because it consumes relatively little energy and produces relatively little environmental pollution per unit transported.

\subsection{Policy Implications}

Based on our findings, we propose some policies to improve the environmental efficiency of the Chinese transportation sector. Our results suggest that the government should implement different energy-saving policies depending on the area or region concerned. Overall, fixed capital investment has a larger influence on the Chinese transportation sector, especially in Shanghai and Jiangsu. These two provinces should increase their investment in the transportation sector, so as to encourage public transportation further and to the excessive use of private cars. Beijing has a greater potential energy saving, and its undesirable output $\mathrm{CO}_{2}$ also has a large influence on environmental efficiency, so Beijing should further promote its energy conservation and emissions reduction policy, impel 
technological innovations in transportation, and upgrade vehicle emission standards. As one of the most developed provinces in China, Guangdong should actively introduce advanced energy-saving technology from overseas to improve environmental efficiency in the transportation sector. For Yunnan province in the west of China, measures should be taken from a variety of aspects to improve its environmental efficiency of the transportation sector, such as strengthening transportation infrastructure construction (passenger rapid transit systems, city and rural transportation systems), and narrowing the regional imbalances in the transportation sector.

The Twelfth Five-Year Plan (2011-2015) will soon be complete, the objective of which is an energy-efficient, environmentally friendly society. The Chinese government has made great efforts to encourage energy conservation and decrease emissions by formulating a series of goals, to which end a series of policies was launched. The Chinese government revised the "Ambient Air Quality Standard" in 2012 in order to strengthen vehicle pollution controls and improve fuel quality and emission standards. For heavy commercial vehicles, the "Fuel Consumption Limits for Heavy Commercial Vehicles" policy came into force on 1 July 2012, and this applies to buses (not including city buses), trucks (not including dump trucks), and semi-trailer towing vehicles designed to have a maximum total mass of more than $3500 \mathrm{~kg}$, and a new standard will be brought into force soon. The "Limits of Fuel Consumption for Passenger Vehicles" and "Fuel Consumption Evaluation Method and Standards for Passenger Vehicles" (the fourth phase) policies were enacted in December 2014 and will be enforced from 1 January 2016. The aims of these policies are for the average fuel consumption of passenger vehicles to reach $5.0 \mathrm{~L} / 100 \mathrm{~km}$ by around 2020 , to save about $35 \times 10^{6}$ tons of fuel and to decrease $\mathrm{CO}_{2}$ emissions by about $113 \times 10^{6}$ tons. China and the USA issued a joint climate change statement at the APEC conference on 12 November 2014 in Beijing [45]. It was stated that a plan will be made to control Chinese $\mathrm{CO}_{2}$ emissions so that they reach a peak as soon as possible, or by about 2030. It was also stated that a plan will be made to increase the ratio of non-fossil fuel energy used for primary energy production in China to about $20 \%$ by 2030 .

\section{Conclusions}

In this paper we used a non-radial DEA model based on an undesirable output perspective with the slacks-based measure to analyze the environmental efficiency of the transportation sectors of 30 Chinese provinces (municipalities and autonomous regions) between 2003 and 2012. Adding undesirable outputs to the objective function meant that the SBM model considering undesirable output was more suitable for evaluating the energy consumption system. In terms of energy efficiency values, we found that these decreased from 2005 and reached a minimum in 2009, before eventually slightly recovering after that. The difference in efficiency values in Chinese provinces is considerable, with Hebei showing the highest average value and Yunnan showing the lowest average value during the study period. The eastern area generally performed better than the central and western areas. We also analyzed the potential decreases in carbon emissions and the potential energy saving in the transportation sectors of the Chinese provinces.

The work presented here has some limitations. First, because the DEA model is used to measure the relative efficiency values, the maximum efficiency measured in this study is only valid relative to the values for other provinces. Environmental efficiency values for China and other countries will be 
calculated in future work. Second, traffic pollutants such as $\mathrm{SO}_{2}, \mathrm{NO}_{\mathrm{x}}, \mathrm{CO}$, particulate matter (PM), and volatile organic compounds (VOC) have caused widespread concern recently, so whether these traffic pollutants should be taken into consideration when calculating the environmental efficiency of the transportation sector considering undesirable output will be a question for further research. The transportation sector includes rail transport, highways, waterways, aviation, and other forms of transport, but, in this study, we only calculated the environmental efficiency of the transportation sector as a whole. Calculating environmental efficiencies for the different forms of transport would make the results more meaningful.

\section{Acknowledgments}

This study was supported by the National Nature Science Foundation of China (No. 40976021) and the Research Project of the State Key Laboratory of Pollution Control and Resources Reuse.

\section{Author Contributions}

Xiaowei Song proposed the original method of the DEA and designed the main stages in the research. Xiaowei Song and Yongpei Hao designed the indicator system and conducted the empirical analysis by collecting the panel data; they also wrote the paper. The third author (corresponding author), Xiaodong Zhu, supervised the whole writing process.

\section{Conflicts of Interest}

The authors declare no conflict of interest.

\section{Appendix}

Table A1. Partial results of the constant return to scale (CCR) model and the slacks-based measure-data envelopment analysis (SBM-DEA) model.

\begin{tabular}{ccccccccccccccc}
\hline \multirow{2}{*}{ Province } & \multicolumn{3}{c}{$\mathbf{2 0 0 3}$} & \multicolumn{2}{c}{$\mathbf{2 0 0 6}$} & \multicolumn{2}{c}{$\mathbf{2 0 0 8}$} & \multicolumn{2}{c}{$\mathbf{2 0 1 0}$} & \multicolumn{2}{c}{$\mathbf{2 0 1 2}$} & \multicolumn{2}{c}{ Mean Value } \\
\cline { 2 - 13 } & CCR & SBM & CCR & SBM & CCR & SBM & CCR & SBM & CCR & SBM & CCR & SBM \\
\hline Beijing & 0.63 & 0.32 & 0.61 & 0.38 & 0.39 & 0.24 & 0.67 & 0.35 & 0.68 & 0.33 & 0.65 & 0.35 \\
Tianjin & 1.00 & 1.00 & 0.74 & 0.51 & 0.51 & 0.39 & 0.84 & 0.63 & 0.64 & 0.49 & 0.75 & 0.62 \\
Hebei & 1.00 & 1.00 & 1.00 & 1.00 & 1.00 & 1.00 & 1.00 & 1.00 & 1.00 & 1.00 & 1.00 & 1.00 \\
Shanxi & 0.46 & 0.29 & 0.94 & 0.67 & 0.66 & 0.38 & 0.54 & 0.38 & 0.54 & 0.37 & 0.65 & 0.45 \\
Inner Mongolia & 0.51 & 0.37 & 0.71 & 0.45 & 0.68 & 0.46 & 0.77 & 0.45 & 0.77 & 0.45 & 0.69 & 0.43 \\
Liaoning & 0.82 & 0.45 & 0.50 & 0.32 & 0.41 & 0.28 & 0.56 & 0.36 & 0.70 & 0.38 & 0.65 & 0.39 \\
Jilin & 0.50 & 0.29 & 0.67 & 0.46 & 0.51 & 0.34 & 0.48 & 0.32 & 0.53 & 0.32 & 0.56 & 0.37 \\
Heilongjiang & 0.78 & 0.38 & 0.64 & 0.38 & 0.48 & 0.33 & 0.49 & 0.32 & 0.66 & 0.33 & 0.63 & 0.37 \\
Shanghai & 0.55 & 0.29 & 0.54 & 0.36 & 0.43 & 0.28 & 0.84 & 0.39 & 1.00 & 1.00 & 0.64 & 0.40 \\
Jiangsu & 0.67 & 0.55 & 0.81 & 0.65 & 0.78 & 0.59 & 1.00 & 1.00 & 1.00 & 1.00 & 0.85 & 0.73 \\
Zhejiang & 0.96 & 0.64 & 0.81 & 0.47 & 0.69 & 0.45 & 0.72 & 0.51 & 0.60 & 0.40 & 0.77 & 0.53 \\
Anhui & 0.54 & 0.41 & 0.88 & 0.71 & 0.77 & 0.66 & 0.78 & 0.53 & 0.65 & 0.39 & 0.74 & 0.58 \\
Fujian & 1.00 & 1.00 & 0.93 & 0.81 & 0.87 & 0.61 & 0.75 & 0.52 & 0.64 & 0.46 & 0.86 & 0.71 \\
Jiangxi & 0.44 & 0.30 & 0.64 & 0.46 & 0.72 & 0.50 & 0.68 & 0.45 & 0.81 & 0.53 & 0.67 & 0.46 \\
\hline
\end{tabular}


Table A1. Cont.

\begin{tabular}{cccccccccccccc}
\hline \multirow{2}{*}{ Province } & \multicolumn{2}{c}{$\mathbf{2 0 0 3}$} & \multicolumn{2}{c}{ 2006 } & \multicolumn{2}{c}{ 2008 } & \multicolumn{2}{c}{ 2010 } & \multicolumn{2}{c}{ 2012 } & \multicolumn{3}{c}{ Mean Value } \\
\cline { 2 - 13 } & CCR & SBM & CCR & SBM & CCR & SBM & CCR & SBM & CCR & SBM & CCR & SBM \\
\hline Shandong & 0.81 & 0.58 & 1.00 & 1.00 & 1.00 & 1.00 & 0.98 & 0.71 & 0.90 & 0.57 & 0.96 & 0.84 \\
Henan & 0.82 & 0.64 & 0.88 & 0.68 & 0.99 & 0.82 & 0.74 & 0.49 & 0.72 & 0.42 & 0.83 & 0.60 \\
Hubei & 0.44 & 0.24 & 0.49 & 0.31 & 0.47 & 0.28 & 0.53 & 0.34 & 0.47 & 0.29 & 0.49 & 0.30 \\
Hunan & 0.78 & 0.44 & 0.76 & 0.48 & 0.49 & 0.37 & 0.59 & 0.42 & 0.61 & 0.43 & 0.66 & 0.44 \\
Guangdong & 0.84 & 0.58 & 0.68 & 0.46 & 0.56 & 0.38 & 0.66 & 0.41 & 0.79 & 0.43 & 0.72 & 0.46 \\
Guangxi & 0.61 & 0.37 & 0.57 & 0.34 & 0.40 & 0.29 & 0.43 & 0.30 & 0.43 & 0.28 & 0.50 & 0.33 \\
Hainan & 0.64 & 0.33 & 0.50 & 0.34 & 0.40 & 0.25 & 0.41 & 0.25 & 0.54 & 0.27 & 0.55 & 0.32 \\
Chongqing & 0.39 & 0.28 & 0.55 & 0.43 & 0.43 & 0.29 & 0.46 & 0.31 & 0.40 & 0.27 & 0.45 & 0.32 \\
Sichuan & 0.59 & 0.41 & 0.64 & 0.44 & 0.46 & 0.32 & 0.36 & 0.22 & 0.33 & 0.19 & 0.51 & 0.34 \\
\hline
\end{tabular}

\section{References}

1. SCPRC. China's Twelfth Five Year Plan for 2011-2015. Available online: http://www.britishchamber.cn/content/chinas-twelfth-five-year-plan-2011-2015-full-english-version (accessed on 6 July 2015).

2. Zhou, P.; Ang, B.W.; Poh, K.L. Slacks-based efficiency measures for modeling environmental performance. Ecol. Econ. 2006, 60, 111-118.

3. Charnes, A.; Cooper, W.W.; Rhodes, E. Measuring the efficiency of decision making units. Eur. J. Oper. Res. 1978, 2, 429-444.

4. Ramli, N.A.; Munisamy, S. Modeling undesirable factors in efficiency measurement using data envelopment analysis: A review. J. Sustain. Sci. Manag. 2013, 8, 126-135.

5. Scheel, H. Undesirable Outputs in Efficiency Valuations. Eur. J. Oper. Res. 2001, 132, 400-410.

6. Tyteca, D. Linear Programming Models for the Measurement of Environmental Performance of Firms-Concepts and Empirical Results. J. Prod. Anal. 1997, 8, 183-197.

7. Ali, A.I.; Seiford, L.M. Translation Invariance in Data Envelopment Analysis. Oper. Res. Lett. 1990, 10, 403-405.

8. Golany, B.; Roll, Y. An application procedure for DEA. Omega 1989, 17, 237-250.

9. Seiford, L.M.; Zhu, J. Modeling Undesirable Factors in Efficiency Evaluation. Eur. J. Oper. Res. 2002, 142, 16-20.

10. Färe, R.; Grosskopf, S.; Lovell, C.A.K.; Pasurka, C. Multilateral Productivity Comparisons When Some Outputs are Undesirable: A Non-Parametric Approach. Rev. Econ. Stat. 1989, 71, 90-98.

11. Chung, Y.H.; Färe, R.; Grosskopf, S. Productivity and Undesirable Outputs: A DDF Approach. J. Environ. Manag. 1997, 51, 229-240.

12. Bian, Y. Efficiency Evaluation with Undesirable Factors based on DEA. In Proceedings of the 4th International Conference on Wireless Communications, Networking and Mobile Computing, Dalian, China, 12-14 October 2008; pp. 1-5.

13. Charnes, A.; Cooper, W.W.; Golany, B.; Seiford, L.; Stutz, J. Foundations of Data Envelopment Analysis for Pareto-Koopmans Efficient Empirical Production Functions. J. Econ. 1985, 30, 91-107.

14. Portela, M.C.A.S.; Thanassoulis, E.; Simpson, G. Negative Data in DEA: A Directional Distance Approach Applied to Bank Branches. J. Oper. Res. Soc. 2004, 55, 1111-1121. 
15. Fukuyama, H.; Weber, W.L. A Slacks-based inefficiency measure for a two-stage system with bad outputs. Omega 2010, 38, 398-409.

16. Färe, R.; Grosskopf, S. Directional distance functions and slacks-based measures of efficiency. Eur. J. Oper. Res. 2010, 200, 320-322.

17. Sueyoshi, T.; Goto, M.; Ueno, T. Performance analysis of US coal-fired power plants by measuring three DEA efficiencies. Energy Policy 2010, 38, 1675-1688.

18. Cooper, W.W.; Park, K.S.; Pastor, J.T. RAM: A Range Adjusted Measure of Inefficiency for Use with Additive Models, and Relations to Other Models and Measures in DEA. J. Prod. Anal. 1999, $11,5-42$.

19. Tone, K. A slacks-based measure of efficiency in data envelopment analysis. Eur. J. Oper. Res. 2001, 130, 498-509.

20. Lozano, S.; Gutiérrez, E. Slacks-based measure of efficiency of airports with airplanes delays as undesirable outputs. Comput. Oper. Res. 2011, 38, 131-139.

21. Mandal, S.K.; Madheswaran, S. Environmental efficiency of the Indian cement industry: An interstate analysis. Energy Policy 2010, 38, 1108-1118.

22. Zhou, P.; Ang, B.W.; Wang, H. Energy and $\mathrm{CO}_{2}$ Emission Performance in Electricity Generation: A Non-radial Directional Distance Function Approach. Eur. J. Oper. Res. 2012, 221, 625-635.

23. Li, L.B.; Hu, J.L. Ecological total-factor energy efficiency of regions in China. Energy Policy 2012, 46, 216-224.

24. Song, M.L.; An, Q.X.; Zhang, W.; Wang, Z.Y.; Wu, J. Environmental Efficiency Evaluation Based on Data Envelopment Analysis: A review. Renew. Sustain. Energy Rev. 2012, 16, 4465-4469.

25. Telle, K.; Larsson, J. Do environmental Regulations Hamper Productivity Growth? How Accounting for Improvements of Plants' Environmental Performance Can Change the Conclusion. Ecol. Econ. 2007, 61, 438-445.

26. Banerjee, S. Environmental Regulation and Technical Efficiency: A Data Envelopment Analysis for Indian Cement Industry. Available online: http://www.isical.ac.in/ eru/erudp/2007-01.pdf (accessed on 13 July 2015).

27. Wang, Y.; Liu, J.; Hansson, L.; Zhang, K.; Wang, R. Implementing Stricter Environmental Regulation to Enhance Eco-efficiency and Sustainability: A Case Study of Shandong Province's Pulp and Paper Industry, China. J. Clean. Prod. 2011, 19, 303-310.

28. Yörük, B.K., Zaim, O. International Regulations and Environmental Performance. Appl. Econ. 2008, 40, 807-822.

29. Burnett, R.D.; Hansen, D.R. Eco-efficiency: Defining a role for environmental cost management. Account. Organ. Soc. 2008, 33, 551-581.

30. Boyd, G.A.; Pang, J.X. Estimating the linkage between energy efficiency and productivity. Energy Policy 2000, 28, 289-296.

31. Boyd, G.A.; Tolley, G.; Pang, J. Plant Level Productivity, Efficiency, and Environmental Performance of the Container Glass Industry. Environ. Resour. Econ. 2002, 23, 29-43.

32. Tongzon, J. Efficiency measurement of selected Australian and other international ports using data envelopment analysis. Transp. Res. A 2001, 35, 107-122. 
33. Merkert, R.; Hensher, D.A. The impact of strategic management and fleet planning on airline efficiency-A random effects Tobit model based on DEA efficiency scores. Transp. Res. A 2011, 45, 686-695.

34. Lin, L.C.; Hong, C.H. Operational performance evaluation of international major airports: An application of data envelopment analysis. J. Air Transp. Manag. 2006, 12, 342-351.

35. Chang, Y.T.; Zhang, N.; Danao, D.; Zhang, N. Environmental efficiency analysis of transportation system in China: A non-radial DEA approach. Energy Policy 2013, 58, 277-283.

36. Chung, W.; Zhou, G.H.; Yeung, I.M.H. A study of energy efficiency of transport sector in China from 2003 to 2009. Appl. Energy 2013, 112, 1066-1077.

37. Farrell, M.J. The measurement of productive efficiency. J. R. Stat. Soc. Ser. A 1957, 120, 253-281.

38. Tone, K. Toronto: Presentation at NAPW III. In Dealing with Undesirable Outputs in DEA: A Slacks-Based Measure (SBM) Approach; National Graduate Institute for Policy Studies: Tokyo, Japan, 2004.

39. Mei, G.P.; Gan, J.Y.; Zhang, N. Metafrontier Environmental Efficiency for China's Regions: A Slack-Based Efficiency Measure. Sustainability 2015, 7, 4004-4012.

40. Jacob, V.; Sharma, S.C.; Grabowski, R. Capital stock estimates for major sectors and disaggregated manufacturing in selected OECD countries. Appl. Econ. 1997, 29, 563-579.

41. Shi, G.M.; Bi, J.; Wang, J.N. Chinese regional industrial energy efficiency evaluation based on a DEA model of fixing non-energy inputs. Energy Policy 2010, 38, 6172-6179.

42. Bian, Y.W.; Yang, F. Resource and environment efficiency analysis of provinces in China: A DEA approach based on Shannon's entropy. Energy Policy 2010, 38, 1909-1917.

43. IPCC. 2006 IPCC Guidelines for National Greenhouse Gas Inventories. Available online: http://www.ipcc-nggip.iges.or.jp/public/2006gl/index.html (accessed on 6 July 2015).

44. Energy Research Institute NDRC. Study on the Sustainable Energy Development and Carbon Emission Scenarios Analysis in China; Energy Research Institute NDRC: Beijing, China, 2007.

45. U.S.-China Joint Announcement on Climate Change. Available online: http://www.fmprc.gov.cn/ mfa_chn/zyxw_602251/t1210034.shtml (accessed on 7 July 2015).

(C) 2015 by the authors; licensee MDPI, Basel, Switzerland. This article is an open access article distributed under the terms and conditions of the Creative Commons Attribution license (http://creativecommons.org/licenses/by/4.0/). 